\title{
ASSESSMENT OF TRANS FATTY ACID LEVELS IN REFINED PALM-BASED OILS AND COMMERCIAL VEGETABLE OILS IN THE MALAYSIAN MARKET
}

\author{
HISHAMUDDIN, E*; ABD RAZAK, R A*; YEOH, C B* and AHMAD TARMIZI, A H*
}

\begin{abstract}
Trans fats consumption is a major concern worldwide due to the deleterious effects associated with increased risks of coronary heart disease. The trans fatty acid (TFA) content of 104 refinery and commercial vegetable oils in the Malaysian market were analysed by gas chromatography. TFA levels in 29 samples of refined, bleached and deodourised palm oil, palm olein, palm stearin and palm kernel olein from palm oil refineries ranged from $0.12 \pm 0.00$ to $0.84 \pm 0.01 \mathrm{~g} / 100 \mathrm{~g}$. Commercially packaged vegetable oils namely palm olein, sunflower, corn, coconut, rice bran, peanut, olive and sesame oils contained less than $1 \mathrm{~g}$ TFA/100 $\mathrm{g}$ while higher TFA levels ranging from 1 to $3 \mathrm{~g} / 100 \mathrm{~g}$ were detected in canola oil, soyabean oil and canola-based oil blend samples. Amongst the premium oils, cold pressed unrefined almond and walnut oils were found to contain TFA levels exceeding $2 \mathrm{~g} / 100 \mathrm{~g}$ while other oils in this category contained TFA less than $1 \mathrm{~g} / 100 \mathrm{~g}$. All retail palm-based vegetable oils and palm-based vegetable fat shortenings except for three samples conformed to the conditions for nutrition claims of low TFA of $1.5 \mathrm{~g} / 100 \mathrm{~g}$ and $0.75 \mathrm{~g} / 100 \mathrm{ml}$ in both solids and liquids, respectively, as regulated in the Malaysian Food Act 1983.
\end{abstract}

Keywords: palm oil, trans fatty acids, vegetable oils.

Received: 14 October 2020; Accepted: 9 March 2021; Published online: 21 June 2021.

\section{INTRODUCTION}

Trans fatty acids (TFA) are defined as unsaturated fatty acids possessing at least one double bond in the trans configuration. TFA are derived primarily from two sources; (1) ruminant trans fats which occur naturally in dairy products and meat from ruminant animals; and (2) industrial trans fats which are produced from the partial hydrogenation of vegetable oils (Mozaffarian et al., 2006). Industrial trans fats or more commonly known as partially hydrogenated vegetable oils (PHO) are found in a myriad of bakery, frozen and fast food products, margarines and shortenings,

\footnotetext{
Malaysian Palm Oil Board,

6 Persiaran Institusi, Bandar Baru Bangi,

43000 Kajang, Selangor, Malaysia.

E-mail: elina@mpob.gov.my
}

packaged snacks and biscuits. In the past, food manufacturers preferred using industrial trans fats as an ingredient in their food formulations as the partial hydrogenation process increases the solidity and reduces rancidity of the oil. This resulted in improved stability and shelf-life of food products containing industrial trans fats (Nishida and Uauy, 2009).

In the last three decades, there has been a growing body of convincing scientific evidence on the health-damaging effects of TFA. Worldwide consumption of trans fats has been strongly associated with an elevated risk of coronary heart disease (CHD) and death from CHD, systemic inflammation, diabetes and cancer (Mozaffarian et al., 2009; De Souza et al., 2015; Islam et al., 2019). Both industrial and ruminant TFAs have been shown to equally raise LDL and lower HDL cholesterols, although controlled human 
studies on the latter are rather limited (Brouwer et al., 2010; World Health Organization and Brouwer, 2016). Recognising the growing epidemic of cardiovascular diseases worldwide, the World Health Organisation (WHO) in 2003 recommended limiting the daily intake of TFA to less than $1 \%$ of total energy intake (Nishida et al., 2004).

Since then, countries such as Denmark, USA and Canada initiated the reduction and elimination of trans fats in food through legislative initiatives involving the implementation of regulations setting maximum limits of trans fat or mandated labelling of trans fats which was subsequently instigated in more than 30 countries (Hendry et al., 2015; Zuchowska-Grzywacz and Kowalska, 2019). The United States Food and Drug Administration (USFDA) revoked the Generally Recognised as Safe (GRAS) status of PHO and banned PHO usage in human food effective June 2018 (USFDA, 2015). The European Parliament adopted a resolution the following year to limit PHO in foods and to establish legal limits for TFAs in food by 2018 (EP, 2016). Starting from 1 April 2021, the European Commission will impose a maximum limit of $2 \mathrm{~g}$ TFA per $100 \mathrm{~g}$ fat in food products intended for the final consumer and food intended for supply to retail, which excludes those naturally occurring trans fat in animal fat (European Commission, 2019).

With the implementation of these government legislations and mandated regulations, worldwide TFA consumption has seen a tremendous decline in the past two decades with an average global trans fat intake lower than the 2003 WHO recommendation of a daily TFA intake limit of $1 \%$ total energy (Craig-Schimdt and Rong, 2009; Wanders et al., 2017; Li, 2019). The WHO in 2018 launched the REPLACE action package which serves to support governments to eliminate industrially produced TFA from the global food supply by 2023 and replacement of TFA with healthier oils and fats through six strategic actions, namely Review, Promote, Legislate, Assess, Create and Enforce (Ghebreyesus and Frieden, 2018). As of 2018, mandatory TFA limits are in effect in 34 countries and passed in 24 additional countries (World Health Organization, 2019). Amongst the South East Asian countries, Thailand and Singapore have banned PHO in their food supply while Indonesia has implemented a national policy commitment to eliminate TFA from their food products (Non-Communicable Diseases Alliance, 2019). In Malaysia, mandatory declaration of TFA and/or the setting of maximum limits of TFA in the food supply are still not in place; however, conditions for nutrient contents for use in nutrition claims are stipulated in the Malaysian Food Act 1983. For food claiming to be low in TFA, the maximum allowable limits are $1.5 \mathrm{~g} / 100$ $\mathrm{g}$ and $0.75 \mathrm{~g} / 100 \mathrm{ml}$ in both solids and liquids, respectively, while a product claiming to be TFAfree must contain no more than $0.1 \%$ TFA in both solids and liquids (Legal Research Board, 2015).

Palm oil products have long been regarded as excellent trans-fat replacement ingredients as they do not require hydrogenation due to the inherent saturated fatty acid components which provide structure to solid fats (Parveez et al., 2020). To date, there are very few studies which have examined TFA levels in commercial food products available in the Malaysian market. One of the earliest studies by Tang (2002) investigated the TFA levels of various palm-based and non-palmbased vegetable oils from local manufacturers and retailers in Malaysia. The author found that the TFA content of palm-based products ranged between $0.25 \%$ and $0.67 \%$ while those of non-palmbased cooking oils were present at a higher range of $0.45 \%$ to $3.85 \%$. Many authors have reported that the major sources of industrial TFA in the Malaysian diet are semi-solid fats and cooking oils, fast foods, bakery products, breakfast cereals, snacks, dairy products and fried foods (Akmar et al., 2013; Azimah et al., 2013; Nurshahbani and Azrina, 2014). The TFA contents of biscuits in the Malaysian market have also been reported in two separate studies by Neo et al. (2007) and Norhayati et al. (2011). These studies reported that locallymade Malaysian biscuits possessed low TFA levels below $1 \%$ as a result of using palm oil in the ingredients whereas imported biscuits were found to contain higher levels of TFA between 0.03 and $3.09 \mathrm{~g} / 100 \mathrm{~g}$ of total fatty acids. Karupaiah et al. (2014) examined the TFA content of 158 Malaysian supermarket food samples comprising fats and oils, dairy products, snacks, soups, confectionery, meat and meat products. Five products within the chocolate, ghee and butter products contained high TFA contents exceeding the $1.5 \mathrm{~g} / \mathrm{kg}$ solids level indicated in the Malaysian Food Standard for a TFA nutrient label claiming a product as low trans.

Realising the need for an updated assessment of TFA levels in commercial cooking oils and fats, the aims of this study were to analyse the current levels of TFA in vegetable oils in the Malaysian market and to investigate the relationship between the levels of TFA and the contents of different fatty acid groups within the oils. It is hoped that this study would establish the present levels of TFA from retail cooking oils and fats which could contribute to the current TFA intake in the Malaysian population. This would provide authorities with an indication on TFA levels in vegetable oil products as a result of changes in refining and processing practices and further support the implementation of a national commitment for the elimination of TFA from food products on the Malaysian market. 


\section{MATERIALS AND METHODS}

\section{Materials}

A total of 104 samples of vegetable oils were sampled in this study. The oils included refined, bleached and deodourised (RBD) palm-based oils and fats obtained from palm oil refineries throughout Malaysia and commercial vegetable oils and fats bought from major supermarkets as well as small sundry shops in the state of Selangor, Malaysia. The samples were collected between 2017 and 2019, and analysed within the same year. All samples were stored at $4^{\circ} \mathrm{C}$ and thoroughly homogenised prior to fatty acid composition analysis.

\section{Fatty Acid Composition Analysis}

The fatty acid composition was analysed according to the American Oil Chemists' Society (AOCS) Official Method Ce 1f-96 (AOCS, 2009). Methyl esters of fatty acids were analysed using an Agilent 6890 Series gas chromatography (GC) system (J\&W Scientific, Folsom, USA) equipped with a flame ionisation detector (FID) (Agilent Technologies, Wilmington, USA) on a fused silica capillary column (BPX-70, $60 \mathrm{~m}$ length $\times 0.25$ $\mathrm{mm}$ i.d., film thickness $0.25 \mu \mathrm{m}$, SGE Inc., Austin, TX). The column temperature was set at $192^{\circ} \mathrm{C}$ while injector (with split ratio 100:1) and detector temperatures were both set at $250^{\circ} \mathrm{C}$. Helium (purity 99.999\%) flowrate was set at $0.8 \mathrm{ml} \mathrm{min}^{-1}$. FAME were identified based on the retention times of FAME mix standards, namely Grain FAME Mix (Supelco, Bellefonte, USA), rapeseed oil reference mixture (AOCS, Urbana, USA), linoleic acid methyl ester isomer mix (Supelco, Bellefonte, USA) and comparisons with earlier literature. Analyses were carried out in duplicate and reported as mean \pm standard deviation (SD). All oil samples analysed in this study were categorised as refined oils and fats, hence the TFA content using the abovementioned procedure was defined as the sum of $\mathrm{C} 18: 1 t, \mathrm{C} 18: 2 t$ and $\mathrm{C} 18: 3 t$ components relative to the total fatty acids present in the oil sample. Results are reported in $\mathrm{g}$ per $100 \mathrm{~g}$ fat.

\section{Statistical Analysis}

One-way analysis of variance (ANOVA) was performed to evaluate significant differences between results using Tukey's test at a confidence level of $95 \% \quad(p<0.05)$. Pearson's correlation coefficient was used to determine the relationship between TFA and selected fatty acid parameters, i.e. saturated fatty acids (SFA), monounsaturated fatty acids (MUFA) and polyunsaturated fatty acids (PUFA). All statistical analyses were conducted using Minitab software (Minitab 16, Minitab Inc., State College, USA).

\section{RESULTS AND DISCUSSION}

\section{Distribution of Trans Fatty Acids Content in RBD Palm-based Oils and Fats from Malaysian Refineries}

The compositions of TFA, TFA isomers, SFA, MUFA and PUFA groups for RBD palm-based samples from Malaysian refineries are presented in Table 1. TFA was detected in all RBD palm-based samples with TFA concentrations varying from 0.12 $\pm 0.00 \mathrm{~g} / 100 \mathrm{~g}$ to $0.84 \pm 0.01 \mathrm{~g} / 100 \mathrm{~g}$. These results agree with Tang (2002) who demonstrated that small amounts of TFA present in refined palm oils are a result of thermal isomerisation due to the relatively high temperatures of up to $260^{\circ} \mathrm{C}$ employed during deodourisation. There was a significant difference between the TFA levels in RBD palm olein and RBD palm kernel olein. Higher TFA levels in RBD palm olein samples compared to that of RBD palm kernel olein can be attributed to higher deodourisation temperatures used during palm oil refining and higher content of PUFA in RBD palm olein compared to RBD palm kernel olein. This is supported by

TABLE 1. COMPOSITION OF TFA, TFA ISOMERS AND FATTY ACID GROUPS OF RBD PALM OIL AND PALM KERNEL OIL PRODUCTS FROM MALAYSIAN PALM OIL REFINERIES

\begin{tabular}{|c|c|c|c|c|c|c|c|c|}
\hline $\begin{array}{l}\text { RBD palm oil } \\
\text { fractions }\end{array}$ & $\begin{array}{c}\text { SFA } \\
(\mathrm{g} / 100 \mathrm{~g})\end{array}$ & $\begin{array}{l}\text { MUFA } \\
(\mathrm{g} / 100 \mathrm{~g})\end{array}$ & $\begin{array}{c}\text { PUFA } \\
(\mathrm{g} / 100 \mathrm{~g})\end{array}$ & $\begin{array}{l}\text { C18:1t } \\
(\mathrm{g} / 100 \mathrm{~g})\end{array}$ & $\begin{array}{l}\text { C18:2t } \\
(\mathrm{g} / 100 \mathrm{~g})\end{array}$ & $\begin{array}{c}\text { C18:3t } \\
(\mathrm{g} / 100 \mathrm{~g})\end{array}$ & $\begin{array}{c}\text { TFA } \\
(\mathrm{g} / 100 \mathrm{~g})\end{array}$ & $\begin{array}{l}\text { Average } \\
\text { TFA } \\
\text { (g/100 g) }\end{array}$ \\
\hline Palm oil $(n=18)$ & $50.38 \pm 0.62$ & $39.27 \pm 1.19$ & $9.99 \pm 0.61$ & $0.05 \pm 0.01$ & $0.34 \pm 0.13$ & $0.09 \pm 0.03$ & $0.24-0.67$ & $0.48 \pm 0.16$ \\
\hline Palm olein $(n=7)$ & $44.62 \pm 1.33$ & $43.94 \pm 0.92$ & $10.99 \pm 0.58$ & $0.07 \pm 0.02$ & $0.45 \pm 0.14$ & $0.11 \pm 0.02$ & $0.39-0.84$ & $0.62 \pm 0.15$ \\
\hline Palm stearin $(n=3)$ & $67.67 \pm 0.22$ & $25.92 \pm 0.26$ & $6.09 \pm 0.06$ & $0.06 \pm 0.03$ & $0.22 \pm 0.01$ & $0.06 \pm 0.01$ & $0.32-0.38$ & $0.34 \pm 0.03$ \\
\hline $\begin{array}{l}\text { Palm kernel olein } \\
(n=1)\end{array}$ & 74.08 & 22.09 & 3.75 & 0.04 & 0.08 & ND & - & 0.12 \\
\hline
\end{tabular}

Note: Values expressed as mean \pm standard deviation. The number of products $(n)$ is descripted within parentheses.

SFA - saturated fatty acid; MUFA - monounsaturated fatty acid; PUFA - polyunsaturated fatty acids; TFA - trans fatty acids; ND - not detected. 
a previous study by Tasan et al. (2011) which showed that PUFA such as linoleic acid (C18:2) and linolenic acid (C18:3) are more prone to geometrical isomerisation during deodourisation. Furthermore, the considerably lower TFA observed in palm kernel fractions can also be ascribed to the milder deodourisation temperatures of $240^{\circ} \mathrm{C}$ and below used during palm kernel oil refining (Tang, 2002).

The average TFA content of RBD palm-based samples in the present study were found to be slightly higher compared to the average TFA for similar sample groups in the study by Tang (2002). The author reported average TFA levels for RBD palm oil, RBD palm olein, RBD palm stearin and RBD palm kernel olein at $0.32 \pm 0.16 \%, 0.30 \pm 0.17 \%$, $0.26 \pm 0.13 \%$ and $0.03 \pm 0.03 \%$, respectively. The higher TFA values observed in this study suggest that there may be differences in refining practices employed by the Malaysian palm oil industry within the last two decades, in particular during the deodourisation step. Wolff (1993) previously showed that TFA formation strongly depends on heating time and deodourisation temperature, thus, prolonged deodourisation time at higher temperatures may increase TFA content of refined oils. Thus, it is possible that the use of higher deodourisation temperatures in the past few decades may have contributed to the rise in TFA levels in the current RBD palm-based samples in this study. All RBD palm-based samples in this study conformed to the condition for nutrition claims of low TFA levels in the Malaysian Food Act 1983 of $0.75 \mathrm{~g}$ per $100 \mathrm{ml}$ liquid. Only one RBD palm olein sample with TFA level of $0.84 \pm 0.01 \mathrm{~g} / 100 \mathrm{~g}$ was found to exceed this limit.

\section{Distribution of Trans Fatty Acids Content in Commercial Cooking Oils and Fats from Malaysian Supermarkets and Sundry Shops}

Table 2 summarises the composition of TFA, TFA isomers and fatty acid groups of selected commercial cooking oils purchased in their final packaging form from supermarkets and sundry shops in Malaysia. The commercial cooking oil samples were grouped into different oil types, namely palm olein, canola oil, sunflower oil, soyabean oil, corn oil, coconut oil, sesame oil, olive oil, peanut oil, rice bran oil, palm-based oil blend, canola-based oil blend, vegetable shortenings and premium oils. The premium oils category comprised of various cold pressed oils, specifically avocado oil, apricot kernel oil, almond oil, organic flaxseed (linseed) oil, unrefined pumpkin oil and safflower oil. The category also included macadamia oil, walnut oil, grapeseed oil, black seed oil and black seed and olive oil blend. TFA was detected in all the commercial cooking oil samples analysed in this study with the exception of cold pressed virgin coconut oil.

TABLE 2. COMPOSITION OF TFA, TFA ISOMERS AND FATTY ACID GROUPS OF COMMERCIAL VEGETABLE OILS IN MALAYSIA

\begin{tabular}{|c|c|c|c|c|c|c|c|c|}
\hline Category & $\begin{array}{c}\text { SFA } \\
(\mathrm{g} / 100 \mathrm{~g})\end{array}$ & $\begin{array}{l}\text { MUFA } \\
(\mathrm{g} / 100 \mathrm{~g})\end{array}$ & $\begin{array}{l}\text { PUFA } \\
(\mathrm{g} / 100 \mathrm{~g})\end{array}$ & $\begin{array}{l}\text { C18:1t } \\
(\mathrm{g} / 100 \mathrm{~g})\end{array}$ & $\begin{array}{c}\text { C18:2t } \\
(\mathrm{g} / 100 \mathrm{~g})\end{array}$ & $\begin{array}{c}\text { C18:3t } \\
(\mathrm{g} / 100 \mathrm{~g})\end{array}$ & $\begin{array}{l}\text { TFA Range } \\
\text { (g/100 g) }\end{array}$ & $\begin{array}{c}\text { TFA } \\
(\mathrm{g} / 100 \mathrm{~g})\end{array}$ \\
\hline Palm olein $(n=14)$ & $43.65 \pm 1.79$ & $44.31 \pm 1.28$ & $11.79 \pm 0.75$ & $0.04 \pm 0.01$ & $0.26 \pm 0.18$ & $0.07 \pm 0.04$ & $0.04-0.86$ & $0.37 \pm 0.22$ \\
\hline Canola oil $(n=4)$ & $7.51 \pm 0.71$ & $61.48 \pm 3.57$ & $30.79 \pm 2.92$ & $0.04 \pm 0.01$ & $0.28 \pm 0.17$ & $1.62 \pm 0.54$ & $1.43-2.96$ & $1.94 \pm 0.70$ \\
\hline Sunflower oil $(n=4)$ & $9.18 \pm 2.41$ & $56.43 \pm 33.53$ & $34.24 \pm 31.08$ & $0.03 \pm 0.02$ & $0.16 \pm 0.15$ & $0.06 \pm 0.03$ & $0.10-0.47$ & $0.24 \pm 0.16$ \\
\hline Soyabean oil ( $n=$ & $15.90 \pm 0.25$ & $24.49 \pm 1.29$ & $59.33 \pm 1.34$ & $0.08 \pm 0.01$ & $0.49 \pm 0.23$ & $1.06 \pm 0.52$ & $1.10-2.15$ & $1.63 \pm 0.74$ \\
\hline Corn oil $(n=4)$ & $14.51 \pm 0.37$ & $32.04 \pm 2.08$ & $53.15 \pm 2.31$ & $0.05 \pm 0.03$ & $0.45 \pm 0.23$ & $0.14 \pm 0.06$ & $0.25-0.97$ & $0.64 \pm 0.30$ \\
\hline Coconut oil $(n=3)$ & $92.23 \pm 2.17$ & $6.24 \pm 1.40$ & $1.52 \pm 0.75$ & $0.04 \pm 0.01$ & $0.03 \pm 0.01$ & $0.05 \pm 0.01$ & $0.00-0.14$ & $0.06 \pm 0.07$ \\
\hline Sesame oil $(n=5)$ & $16.10 \pm 0.58$ & $41.68 \pm 1.30$ & $41.59 \pm 1.55$ & $0.18 \pm 0.12$ & $0.27 \pm 0.15$ & $0.33 \pm 0.00$ & $0.10-0.76$ & $0.52 \pm 0.27$ \\
\hline Olive oil $(n=8)$ & $15.62 \pm 0.95$ & $74.49 \pm 2.96$ & $9.66 \pm 2.21$ & $0.07 \pm 0.07$ & $0.07 \pm 0.04$ & $0.07 \pm 0.04$ & $0.04-0.45$ & $0.19 \pm 0.14$ \\
\hline $\begin{array}{l}\text { Palm-based oil blend } \\
(n=6)\end{array}$ & $36.69 \pm 6.35$ & $41.45 \pm 3.42$ & $21.54 \pm 9.63$ & $0.05 \pm 0.02$ & $0.43 \pm 0.25$ & $0.20 \pm 0.18$ & $0.32-1.04$ & $0.67 \pm 0.33$ \\
\hline $\begin{array}{l}\text { Canola-based oil blend } \\
(n=6)\end{array}$ & $10.53 \pm 3.71$ & $54.21 \pm 8.46$ & $34.99 \pm 7.97$ & $0.03 \pm 0.02$ & $0.23 \pm 0.19$ & $1.13 \pm 0.32$ & $1.00-2.06$ & $1.38 \pm 0.39$ \\
\hline Premium oils ( $n=11)$ & $12.22 \pm 3.78$ & $45.72 \pm 26.13$ & $41.66 \pm 27.81$ & $0.04 \pm 0.03$ & $0.37 \pm 0.62$ & $0.37 \pm 0.76$ & $0.01-2.64$ & $0.64 \pm 0.93$ \\
\hline $\begin{array}{l}\text { Vegetable fat } \\
\text { shortenings }(n=5)\end{array}$ & $51.62 \pm 13.79$ & $31.42 \pm 6.34$ & $16.70 \pm 19.28$ & $0.06 \pm 0.02$ & $0.40 \pm 0.20$ & $0.26 \pm 0.36$ & $0.34-1.37$ & $0.71 \pm 0.44$ \\
\hline Peanut oil $(n=1)$ & 16.69 & 61.65 & 21.42 & 0.04 & 0.19 & 0.09 & 0.32 & 0.32 \\
\hline Rice bran oil $(n=1)$ & 23.88 & 41.89 & 34.17 & 0.13 & 0.18 & 0.07 & 0.39 & 0.39 \\
\hline
\end{tabular}

Note: Values are expressed as mean \pm standard deviation. The number of products $(n)$ is descripted within parentheses.

SFA - saturated fatty acid; MUFA - monounsaturated fatty acid; PUFA - polyunsaturated fatty acids; TFA - trans fatty acids. 
Among the 75 commercial cooking oils analysed, the highest TFA levels were found in canola oil, followed by soyabean oil and canola-based oil blends. This can be attributed to significantly higher contents of $\mathrm{C} 18: 3 t$ in these three oil categories compared to all other oils. High TFA contents in soyabean and canola oils are primarily caused by the geometrical isomerisation of their inherently high PUFA contents during deodourisation at temperatures above $200^{\circ} \mathrm{C}$ (Wolff, 1992; Ceriani and Meirelles, 2007). Higher concentrations of $\alpha$-linolenic acid are present in canola oils and their bonds are more labile compared to that of linoleic acid, resulting in higher isomerisation degrees of $\alpha$-linolenic acid (Kemény et al., 2001). Hénon et al. (1999) reported that linolenic acid isomerisation in canola oil increases greatly beyond deodourisation temperatures of $220^{\circ} \mathrm{C}-230^{\circ} \mathrm{C}$. Similar TFA levels were observed in US canola oils (TFA range 0.73-4.16 $\mathrm{g} / 100 \mathrm{~g}$ ) as reported by O'Keefe et al. (1994). The TFA of soyabean oil in this study were comparable to values reported earlier by Tang (2002) (TFA range 1.63-3.83 g/100 g), Martin et al. (2008) for Brazilian soyabean oils (TFA range $0.83-2.58 \mathrm{~g} / 100 \mathrm{~g}$ ) and Hou et al. (2012) for soyabean oil from China (TFA range 0.23-3.11 g/100 g). However, the values were lower than those observed by Wolff (1993) for soyabean oil from Great Britain (TFA range 1.73-2.52 g/100 g) and those by Akmar et al. (2013) and Azimah et al. (2013), both reporting a mean TFA of $5.79 \mathrm{~g} / 100 \mathrm{~g}$ for one soyabean oil sample in Malaysia. This could be due to the wide variation in processing conditions by refiners which give rise to varying TFA levels in different soyabean oil brands in Malaysia.

Commercial vegetable oils which showed TFA below $0.5 \mathrm{~g} / 100 \mathrm{~g}$ include rice bran oil, palm olein, peanut oil, sunflower oil and coconut oil in descending order. The lowest TFA level amongst all commercial oils analysed was detected in coconut oil. The coconut oils in this study contained a significantly higher content of SFA (more than 90\%) and relatively low amount of PUFA (less than 3\%) compared to all other commercial oils. This was expected since coconut oil is well-known for its high saturated fatty acid content, comprising mainly medium-chain saturated fatty acids such as lauric acid and myristic acid which give the oil higher thermal resistance. As a consequence, coconut oil requires deodourisation at lower temperatures between $240^{\circ} \mathrm{C}-250^{\circ} \mathrm{C}$ (Withana-Gamage et al., 2005). The coconut oil category in this study included one cold pressed virgin coconut oil sample where TFA was not detected. This can be explained through the nature by which virgin coconut oil is obtained from fresh, mature kernel of the coconut by mechanical or natural means, with or without the application of heat and which does not result in the alteration of the nature of the oil (Phillipines National Standard, 2007). The TFA in coconut oils in our study agreed with those reported by Dayrit et al. (2011) for coconut oils from Phillipines and Marina et al. (2009) for Malaysian and Indonesian coconut oils.

Palm olein, rice bran and peanut oils contained similar TFA levels, however the SFA content in palm olein was higher compared to the latter two. There were no significant differences between the MUFA and PUFA levels among the three oil categories with palm olein containing much lower PUFA levels compared to the other two oils. The major TFA isomer contributing to total TFA in all three oil types was C18:2t. As there was only one sample each for rice bran and peanut oils, there was insufficient data to draw a conclusion from these oils. However, results from this study were similar to that of Huang et al. (2016) who reported TFA levels ranging from $0.10-1.62 \mathrm{~g} / 100 \mathrm{~g}$ and $0.1-1.63 \mathrm{~g} / 100 \mathrm{~g}$ for palm oils and peanut oils in China, respectively.

A substantial reduction in the mean TFA was observed in sunflower oils to below $0.3 \mathrm{~g} / 100 \mathrm{~g}$ in this study in comparison to the TFA levels for sunflower oils in Malaysia reported by Tang (2002) which exceeded $1 \%$, and that of French sunflower oils (mean $0.5 \mathrm{~g} / 100 \mathrm{~g}$ ) in the study by Vingering et al. (2010). It is worth noting that the sunflower oil samples analysed in this study included conventional as well as high oleic sunflower oils which contained approximately $27 \%$ and $85 \%$ MUFA on average, respectively. The major TFA isomer in sunflower oil samples were those of C18:2t. The TFA observed in sunflower oils in this study could be attributed to the various sunflower oil species and possibly different refining methods used for the oils. High oleic sunflower oil predominantly contains oleic acid which is less prone to isomerisation compared to PUFA (Martinčič et al., 2008). Tasan and Demirci (2003) demonstrated that physically refined sunflower oils contained a higher level of TFA $(2.56 \pm 0.25 \mathrm{~g} / 100 \mathrm{~g})$ compared to chemically refined sunflower oils $(0.76 \pm 0.27 \mathrm{~g} / 100 \mathrm{~g})$ due to the high temperature applied in the last stage of physical refining. The C18:3t range in sunflower oil samples was observed to be significantly lower compared to that of canola and soyabean oils and equivalent to that of palm olein. Optimisation of processing conditions during the deacidification step of physical refining of sunflower oil, through the application of lower deodourisation temperatures and shorter heating times could minimise the degree of isomerisation of PUFA in sunflower oils (Ceriani et al., 2008) and this may explain the reduced TFA levels of sunflower oils in this study.

A very low TFA level averaging at $0.19 \mathrm{~g} / 100 \mathrm{~g}$ was found for the olive oil category and this could be due to the significantly higher MUFA content (more than 70\%) compared to other commercial oils. The olive oils in this study included extra virgin olive oil, virgin + refined olive oil and olive pomace oil based on the labels provided on the packaging. Virgin olive 
oils are obtained from the fruit of the olive tree solely by mechanical or other physical means, particularly thermal conditions that do not lead to alterations in the oil and have not undergone any treatment other than washing, decanting, centrifuging and filtration (Codex Alimentarius, 2015). On the other hand, olive pomace oil is obtained by treating olive pomace with solvents other than halogenated solvents or by other physical treatments, to the exclusion of oils obtained by re-esterification processes and of any mixture with oils of other kinds. The production of olive pomace oil also involves a drying step using hot drying gases normally within a temperature range of between $400^{\circ} \mathrm{C}$ and $800^{\circ} \mathrm{C}$ (Sánchez Moral and Ruiz Méndez, 2006). Amongst the olive oils sampled, extra virgin olive oils $(n=3)$ contained the lowest levels of TFA (less than $0.1 \mathrm{~g} / 100 \mathrm{~g}$ ), while virgin olive oils $(n=3)$ showed TFA levels less than $0.3 \mathrm{~g} / 100 \mathrm{~g}$. The highest level of TFA was observed in olive pomace oil $(n=1)$ at $0.45 \mathrm{~g} / 100 \mathrm{~g}$ oil. The varying TFA levels within the different types of olive oils are indicative of the different extraction processes and whether the oils had undergone any thermal treatment. TFA levels of all olive oils in this study were lower than that reported by Azimah et al. (2013) and Akmar et al. (2013) at $0.79 \mathrm{~g} / 100$ $\mathrm{g}$ and fell within the TFA ranges specified in the Codex Standard for Olive Oils and Olive Pomace Oils (Codex Alimentarius, 2015).

From the 14 commercial vegetable oil categories, five oil categories were found to contain TFA levels between $0.5-1.0 \mathrm{~g} / 100 \mathrm{~g}$. These included vegetable fat shortenings, palm-based oil blends, corn oil, premium oils and sesame oil in descending order. There were no significant differences $(p<0.05)$ between the TFA levels of these oil categories, however vegetable shortenings contained a significantly higher SFA content followed by palmbased blended cooking oils. This can be explained by the presence of palm-based solid fraction with $50 \%-60 \%$ SFA content as one of the solid fat ingredients used in four out of five of the vegetable shortenings samples (individual results not shown). Only one vegetable shortening sample contained fully hydrogenated palm oil and soyabean oil as indicated in its ingredients list with over 50\% PUFA. This consequently gave the highest TFA level of 1.37 $\mathrm{g} / 100 \mathrm{~g}$ within this oil category. It is important to note that this study only considered shortenings derived from vegetable oils and fats in order to avoid the naturally occurring ruminant TFA that are usually present in dairy products.

TFA levels above $2 \mathrm{~g} / 100 \mathrm{~g}$ were found in two out of the 13 premium oil samples (individual results not shown in Table 2), specifically cold pressed unrefined almond oil $(2.18 \mathrm{~g} / 100 \mathrm{~g})$ and walnut oil $(2.64 \mathrm{~g} / 100 \mathrm{~g})$. As the almond oil was cold pressed and unrefined, one would expect a significantly low TFA value for the almond oil as TFA levels below
$0.3 \mathrm{~g} / 100 \mathrm{~g}$ was detected in all the other cold pressed oils, i.e., avocado, apricot, flaxseed, pumpkin seed and safflower oils. A possible explanation for the presence of TFA in cold pressed oils can be a result from mixing oils that have been deodourised under different conditions in the same tank or may be due to their storage in unswept tanks (Wolff, 1993).

The TFA of walnut oil in our study was higher than those reported by Wolff (1993) (range 0.84$1.83 \mathrm{~g} / 100 \mathrm{~g}$ ) for German and French walnut oils and Vingering et al. (2010) (range 0.9-1.7 g/100 g oil) for French walnut oil. The walnut oil sample in this study contained about 73\% PUFA and the TFA value was mainly contributed by C18:3t. TFA was present at an average of less than $1 \mathrm{~g} / 100 \mathrm{~g}$ in all other oils in the premium cooking oil category. The large variation in TFA values between commercial oil samples in this study may be influenced by the differences in oil species, processing conditions prior to packaging as well as any additional ingredients such as anti-oxidants or anti-clouding agents used in the oils (Azimah et al., 2013). The nutrient conditions for claiming low TFA is met in all retail cooking oils and fats with the exception of soyabean oils, canola oils, canola-based blended oils and one sample of palm olein blend, walnut oil, cold pressed unrefined almond oil and vegetable shortening containing soyabean oil.

\section{Relationship of TFA with Different Fatty Acid Groups}

In this study, Pearson correlation analysis was carried out to determine the relationship between TFA with fatty acid groups SFA, MUFA, PUFA, as well as selected PUFA, namely C18:1, C18:2 and C18:3. The strength of the relationship between variables tested is expressed as Pearson correlation coefficient $(r)$. Correlation between variables were defined as follows: very weak $(0.0<r<0.3)$, weak $(0.3<r<0.5)$, moderate $(0.5<r<0.7)$, strong $(0.7<r<0.9)$ and very strong $(r>0.9)$ (Zady, 2000). The relationships were considered significant if $p$-value $<0.05$.

TABLE 3. PEARSON CORRELATIONS BETWEEN TFA AND DIFFERENT FATTY ACID GROUPS AND UNSATURATED FATTY ACIDS IN RBD PALM-BASED PRODUCTS FROM MALAYSIAN PALM OIL REFINERIES

\begin{tabular}{ccc}
\hline Parameters & $r$ & $p$-value \\
\hline SFA & -0.549 & 0.002 \\
MUFA & 0.511 & 0.005 \\
PUFA & 0.587 & 0.001 \\
C18:1 & 0.509 & 0.005 \\
C18:2 & 0.581 & 0.001 \\
C18:3 & -0.117 & 0.546 \\
\hline
\end{tabular}

Note: TFA - trans fatty acids. 
Table 3 tabulates results from the Pearson correlation analyses between the levels of TFA and SFA, MUFA, PUFA, C18:1, C18:2 and C18:3 for all samples of RBD palm-based oils from Malaysian palm oil refineries. MUFA and PUFA showed significant moderate positive correlations with TFA ( $r=0.511$ and $r=0.587$, respectively) while SFA displayed a significant moderate inverse correlation $(r=-0.549)$, all showing $p$-value $<0.05$. The levels of C18:1 and C18:2 fatty acids both exhibited moderate positive correlations with TFA $(r=0.509$ and $r=0.581$, respectively) and the correlations were significant ( $p$-value $<0.05)$. On the other hand, C18:3 showed a very weak inverse correlation $(r=-0.117)$ with TFA and the correlation was insignificant. It is worth noting that the levels of $\mathrm{C} 18: 3$ present in the RBD palm-based samples were very low, ranging on average between 0.00 to $0.17 \mathrm{~g} / 100 \mathrm{~g}$ total fat.

There were large variations in the TFA content found in the palm-based samples from Malaysian refineries produced by different manufacturers, presumably using dissimilar processing conditions. According to Gibon (2012), palm oils which undergo physical refining are more prone to form TFA compared to the chemical route due to the more severe thermal treatments applied during physical refining. Chemical refining involves the application of milder temperatures of between $220^{\circ} \mathrm{C}$ and $240^{\circ} \mathrm{C}$ compared to physical refining and Gibon et al. (2007) reported that a typical mean value of $0.6 \mathrm{~g} / 100 \mathrm{~g}$ TFA was found in commercial palm oil products refined at $260^{\circ} \mathrm{C}-275^{\circ} \mathrm{C}$ with short residence times of 45-90 mins. TFA formation can significantly accelerate if higher temperatures and longer residence times are employed. This was further demonstrated by Siew and Mohammad (1989) for palm olein and palm mid fraction which showed TFA values as high as $2.1 \mathrm{~g} / 100 \mathrm{~g}$ and 1.5 $\mathrm{g} / 100 \mathrm{~g}$, respectively, when processed at $280^{\circ} \mathrm{C}$.

In the case of commercial cooking oils, Pearson correlation coefficients between TFA and different fatty acid groups as well C18:1, C18:2 and C18:3 for all commercial vegetable oil samples are shown

TABLE 4. PEARSON CORRELATIONS BETWEEN TFA AND DIFFERENT FATTY ACID GROUPS AND UNSATURATED FATTY ACIDS IN COMMERCIAL VEGETABLE OIL SAMPLES

\begin{tabular}{ccc}
\hline Parameters & $r$ & $p$-value \\
\hline SFA & -0.329 & 0.004 \\
MUFA & -0.079 & 0.501 \\
PUFA & 0.405 & 0.000 \\
C18:1 & -0.074 & 0.529 \\
C18:2 & 0.321 & 0.005 \\
C18:3 & 0.240 & 0.039 \\
\hline
\end{tabular}

Note: TFA - trans fatty acids. in Table 4. SFA yielded a weak negative correlation with TFA ( $r=-0.329)$ while PUFA, C18:2 and C18:3 displayed weak positive correlations $(r=0.405$; $r=0.321 ; r=0.240$, respectively) with TFA, and all these correlations were significant $(p<0.05)$. This indicates that commercial vegetable oils with higher SFA tend to have lower TFA content and vice versa for oils containing higher PUFA concentration. These observations are in agreement with the study by Akmar et al. (2013) on the TFA content of selected foods in Malaysia. The authors concluded that high TFA prevailed in oils with low saturated fatty acids content. Furthermore, it was observed that the TFA in all commercial vegetable oil samples were not associated with MUFA $(r=-0.079)$ and C18:1 $(r=-0.074)$. It is important to note that the majority of commercial yegetable oil samples in this study consisted primarily of refined oils. This observation appears to be consistent with Djikstra (2008) who reported that the main fatty acid to isomerise during hydrogenation is the monounsaturated oleic acid (C18:1). Previous studies have also shown that trans MUFA are generally produced by hydrogenation of vegetable oils or biohydrogenation in ruminants, whereas trans PUFA are formed as a result of deodourisation of oils or during frying treatments (Stender et al., 2008; Chen et al., 2014). These results suggest that the TFA present in commercial vegetable oils in this study were mainly associated with the levels of PUFA (C18:2 and C18:3) and not MUFA (C18:1).

\section{CONCLUSION}

The majority of palm-based cooking oils in Malaysia contained TFA below $1 \mathrm{~g} / 100 \mathrm{~g}$ and were found to conform to the conditions for nutrition claims of low TFA in solid and liquid products, respectively, as regulated in the Malaysian Food Act 1983. All soyabean, canola and canola-based blended oils as well as walnut and cold-pressed almond oils sampled contained TFA levels exceeding $1 \mathrm{~g} / 100 \mathrm{~g}$. In general, PUFA exhibited significant moderate positive correlations with TFA while SFA showed significant moderate inverse correlations with TFA in all oil categories. These findings indicate that the TFA in the oil samples were mostly generated through refining at high deodourisation temperatures and not through partial hydrogenation. Thus, it is imperative that vegetable oil manufacturers reassess the thermal conditions employed during processing in order to minimise the isomerisation of linoleic and linolenic acids. An overview of the overall TFA levels in various vegetable oils in Malaysia is crucial for manufacturers to evaluate current refining practices to meet the recommended TFA levels by WHO. Results evidently show that palm-based 
oils and fats continue to be excellent alternative sources to $\mathrm{PHO}$ in the global quest to eliminate trans fat consumption by 2023. In addition, the findings provide further data in support of the national health authority for the implementation of a national commitment to eliminate TFA from food products on the Malaysian market.

\section{ACKNOWLEDGEMENT}

The authors wish to thank the Director-General of the MPOB for permission to publish this article. Technical assistance from the Innovative Products Group is gratefully acknowledged. The authors would like to extend their sincere appreciation to MPOB for funding this research.

\section{REFERENCES}

Akmar, Z D; Norhaizan, M E; Azimah, R; Azrina, A and Chan, Y M (2013). The trans fatty acids content of selected foods in Malaysia. Malays. J. Nutr., 19: 87-98.

AOCS Official Method Ce 1f-96 (2009). Cis and trans fatty acids in oils and fats by capillary GC. AOCS Official Methods and Recommended Practices of the AOCS. $7^{\text {th }}$ Edition. The American Oil Chemists' Society, Urbana, USA.

Azimah, A; Azrina, A; Norhaizan, M E; Sokhini, M A and Daud, A Z (2013). Industrially produced trans fatty acids: Major potential sources in Malaysian diet. Int. Food Res. J., 20: 1157-1164.

Brouwer, I A; Wanders, A J and Katan, M B (2010). Effect of animal and industrial trans fatty acids on HDL and LDL cholesterol levels in humans A quantitative review. PLOS ONE, 5: e9434. DOI: https: / / doi.org/10.1371/journal.pone.0009434.

Ceriani, R and Meirelles, A J (2007). Formation of trans PUFA during deodorization of canola oil: A study through computational simulation. Chem. Eng. Process, 46: 375-385. DOI: https: / / doi.org/10.1016/j. cep.2006.05.023.

Ceriani, R; Costa, A M and Meirelles, A J A (2008). Optimization of the physical refining of sunflower oil concerning the final contents of trans-fatty acids. Ind. Eng. Chem. Res., 47: 681-692.

Chen, Y; Yang, Y; Nie, S; Yang, X; Wang, Y; Yang, M; Chang, L and Xie, M (2014). The analysis of trans fatty acid profiles in deep frying palm oil and chicken fillets with an improved gas chromatography method. Food Control, 44: 191-197. DOI: https: / / doi. org/10.1016/j.foodcont.2014.04.010.
Codex Alimentarius (2015). Codex Standard for Olive Oils and Olive-pomace Oils (CODEXSTAN 33-1981). http://www.fao.org/fao-whocodexalimentarius / sh-proxy / en / ?lnk=1\&url=htt ps $\% 253 \mathrm{~A} \% 252 \mathrm{~F} \% 252 \mathrm{Fw}$ orkspace.fao.org $\% 252 \mathrm{Fsit}$ es $\% 252$ Fcodex $\% 252$ FStandards $\% 252$ FCXS $\% 2$ B331981\%252FCXS_033e.pdf, accessed on 15 May 2020.

Craig-Schmidt, M C and Rong, Y (2009). Evolution of worldwide consumption of trans fatty acids. Trans Fatty Acids in Human Nutrition (Destaillats F; Sébédio, J-L; Dionisi, F; Chardigny, J-M eds.). $2^{\text {nd }}$ ed., Woodhead Publishing, Cambridge. p. 329-380. DOI: https: / / doi.org/10.1533/9780857097873.329.

Dayrit, F M; Dimzon, I K D; Valde, M F; Santos, J E R; Garrovillas, M J M and Villarino, B J (2011). Quality characteristics of virgin coconut oil: Comparisons with refined coconut oil. Pure Appl. Chem., 83: 17891799. DOI:https:// doi.org/10.1351/PAC-CON-1104-01.

De Souza, R J; Mente, A; Maroleanu, A; Cozma, A I; Ha, V; Kishibe, T; Uleryk, E; Budylowski, P; Schünemann, H; Beyene, J and Anand, S S (2015). Intake of saturated and trans unsaturated fatty acids and risk of all cause mortality, cardiovascular disease, and type 2 diabetes: systematic review and meta-analysis of observational studies. BMJ, 351: h3978. DOI: https: / / doi.org/10.1136/bmj.h3978

Dijkstra, A J (2008). Controlling physical and chemical properties of fat blends through their triglyceride compositions. Trans Fatty Acids (Dijkstra, A J; Hamilton, R J; Hamm, W eds.). Blackwell Publishing, Oxford. p. 132-146.

European Commission (2019). Commission regulation (EU) 2019/649 of 24 April 2019 amending Annex III to Regulation (EC) No 1925/2006 of the European Parliament and of the Council as regards trans fat, other than trans fat naturally occurring in fat of animal origin, OJ L110/17.

European Parliament (EP) (2016). European Parliament resolution of 26 October 2016 on trans fats (TFAs) (2016/2637(RSP)).

Ghebreyesus, T A and Frieden, T R (2018). REPLACE: A roadmap to make the world trans fat free by 2023. Lancet, 391: 1978-1980. DOI: https:/ / doi.org/10.1016/S0140-6736(18)31083-3.

Gibon, V; De Greyt, W and Kellens, M (2007). Palm oil refining. Eur. J. Lipid Sci. Technol., 109: 315-335. DOI: https: / / doi.org/10.1002/ ejlt.200600307.

Gibon, V (2012). Palm oil and palm kernel oil refining and fractionation technology. Palm Oil (Lai, O-M; 
Tan, C-P; Akoh, C C eds.). AOCS Press, Champaign. p. 329-375. DOI: https:// doi.org/10.1016/B978-09818936-9-3.50015-0.

Hendry, V L; Almíron-Roig, E; Monsivais, P; Jebb, S A; Benjamin Neelon, S E; Griffin, S J and Ogilvie, D B (2015). Impact of regulatory interventions to reduce intake of artificial trans-fatty acids: A systematic review. Am. J. Public Health, 105: e32-e42. DOI: https:/ / doi.org/10.2105 / AJPH.2014.302372.

Hénon, G; Kemény, Z; Recseg, K; Zwobada, F and Kovari, K (1999). Deodorization of vegetable oils. Part I: Modelling the geometrical isomerization of polyunsaturated fatty acids. J. Amer. Oil Chem. Soc., 76: 73-81. DOI: https: / doi.org/10.1007 / s11746-9990050-2.

Hou, J C; Wang, F; Wang, Y T; Xu J and Zhang, C W (2012). Assessment of trans fatty acids in edible oils in China. Food Control, 25: 211-215. DOI: https: / / doi. org/10.1016/j.foodcont.2011.10.044.

Huang, X; Nie, S; Yang, M; Xie, J; Li, C and Xie, M (2016). Are Chinese edible oils safe? A survey of trans fatty acid contents in Chinese edible oils. Food Sci. Biotechnol., 25: 631-636. DOI: https:/ / dx.doi.org /10.1007\%2Fs10068-016-0088-5.

Islam, M A; Amin, M N; Siddiqui, S A; Hossain, M P; Sultana, F and Kabir, M R (2019). Trans fatty acids and lipid profile: A serious risk factor to cardiovascular disease, cancer and diabetes. Diabetes Metab. Syndr., 13: 1643-1647. DOI: https: / / doi.org/10.1016/j.dsx.2019.03.033.

Karupaiah, T; Tan, H K; Ong, W W; Tan, C H and Sundram, K (2014). Trans fatty acid content in Malaysian supermarket foods: A field-to-laboratory approach in assessing food risk. Food Addit. Contam. Part A Chem. Anal., 31: 1375-1384. DOI: https: / / doi.org/10.1080/19440049.2014.929183.

Kemény, Z S; Recseg, K; Henon, G; Kővári, K and Zwobada, F (2001). Deodorization of vegetable oils: prediction of trans polyunsaturated fatty acid content. J. Amer. Oil Chem. Soc., 78: 973-979. DOI: https:/ / doi.org/10.1007 / s11746-001-0374-0.

Legal Research Board (2015). Food Act 1983 (Act 281); E Food Regulations 1985: as at 20 February 2015. International Law Book Services, Kuala Lumpur. http: / / www.agc.gov.my / agcportal / uploads / files / Publications / LOM / EN / Act $\% 20281 \% 20-\% 20$ Food\%20Act $\% 201983 . p d f$

Li, C (2019). Global surveillance of trans-fatty acids. Prev. Chronic Dis., 16. DOI: http://dx.doi. org/10.5888/pcd16.190121.
Marina, A M; Che Man, Y B; Nazimah, S A H and Amin, I (2009). Chemical properties of virgin coconut oil. J. Amer. Oil Chem. Soc., 86: 301-307. DOI: https: / / doi.org/10.1007 / s11746-009-1351-1.

Martin, C A; Visentainer, J V; Oliveira, A N D; Oliveira, C C D; Matsushita, M and Souza, N E D (2008). Fatty acid contents of Brazilian soybean oils with emphasis on trans fatty acids. J. Braz. Chem. Soc., 19: 117-122. DOI: https://doi.org/10.1590/ S0103-50532008000100017.

Martinčič, V; Golob, J; de Greyt, W; Verhé, R; Knez, S; Van Hoed, V; Žilnik L F; Potočnik, K; Hraš, A R and Ayala, J V (2008). Optimization of industrialscale deodorization of high-oleic sunflower oil via response surface methodology. Eur. J. Lipid Sci. Technol., 110: 245-253. DOI: https:// doi. org / 10.1002/ ejlt.200700194.

Mozaffarian, D; Katan, M B; Ascherio, A; Stampfer, M J and Willett, W C (2006). Trans fatty acids and cardiovascular disease. N. Engl. J. Med., 354: 16011613. DOI: https:/ / doi.org/10.1056/ nejmra054035.

Mozaffarian, D; Aro, A and Willett, W C (2009). Health effects of trans-fatty acids: experimental and observational evidence. Eur. J. Clin. Nutr., 63: S5-S21. DOI: https://doi.org/10.1038/ sj.ejcn.1602973.

Neo, Y P; Tan, C H and Ariffin, A (2007). Fatty acid composition of five Malaysian biscuits (cream crackers) with special reference to trans-fatty acids. ASEAN Food J., 14: 197-204.

Nishida, C; Uauy, R; Kumanyika, S and Shetty, P (2004). The joint WHO/FAO expert consultation on diet, nutrition and the prevention of chronic diseases: process, product and policy implications. Public Health Nutr., 7: 245-250. DOI: https://doi. org / 10.1079/ PHN2003592.

Nishida, C and Uauy, R (2009). WHO scientific update on health consequences of trans fatty acids: introduction. Eur. J. Clin. Nutr., 63: S1-S4. DOI: https: / / doi.org/10.1038/ ejcn.2009.13.

Non-Communicable Diseases (NCD) Alliance (2019). Trans fat free by 2023: Case studies in trans-fat elimination, https://ncdalliance.org/ resources/TransFatFree2023Report, accessed on 15 May 2020.

Norhayati, M; Azrina, A; Norhaizan, M E and Muhammad Rizal, R (2011). Trans fatty acids content of biscuits commercially available in Malaysian market and comparison with other countries. Int. Food Res. J., 18: 1097-1103. 
Nurshahbani, S S and Azrina, A (2014). Trans fatty acids in selected bakery products and its potential dietary exposure. Int. Food Res. J., 21: 2175-2181.

O'Keefe, S; Gaskins-Wright, S; Wiley, V and Chen, I (1994). Levels of trans geometrical isomers of essential fatty acids in some unhydrogenated US vegetable oils. J. Food Lipids, 1: 165-176. DOI: https: / / doi.org/10.1111/j.1745-4522.1994.tb00244.x.

Parveez, A G K; Hishamuddin, E; Loh, S K; OngAbdullah, M; Mohamed Salleh, K; Zanal Bidin, M N I; Sundram, S; Azizul Hasan, Z A and Idris, Z (2020). Oil palm economic performance in Malaysia and R\&D progress in 2019. J. Oil Palm Res., 32: 159-190. DOI: https: / / doi.org/10.21894/jopr.2020.0032.

Philippine National Standard (2007). Virgin Coconut Oil (VCO) (PNS/BAFPS 22:2007/ ICS 67.200.10. http:/ / spsissuances.da.gov.ph/index.php/daphilippine-national-standards / 1087-pns-bafs-222007-vco-revised, accessed 14 May 2020.

Sánchez Moral, P and Ruiz Méndez, M (2006). Production of pomace olive oil. Grasas Y Aceites, 57: 47-55. DOI: https:/ / doi.org/10.3989/ gya.2006.v57. i1.21.

Siew, W L and Mohammad, Y (1989). Effects of refining on chemical and physical properties of palm oil products. J. Amer. Oil Chem. Soc., 66: 11161119. DOI: https: / / doi.org/10.1007/bf02670096.

Stender, S; Astrup, A and Dyerberg, J (2008). Ruminant and industrially produced trans fatty acids: health aspects. Food Nutr. Res., 52: 1651. DOI: https: / / dx.doi.org/10.3402\%2Ffnr.v52i0.1651.

Tang, T S (2002). Fatty acid composition of edible oils in the Malaysian market, with special reference to the trans-fatty acids. J. Oil Palm Res., 14: 1-8.

Tasan, $\mathrm{M}$ and Demirci, $\mathrm{M}$ (2003). Trans FA in sunflower oil at different steps of refining. J. Amer. Oil Chem. Soc., 80: 825-828. DOI: https://doi. org / 10.1007 / S11746-003-0779-9.

Tasan, M; Gecgel, U and Demirci, M (2011). Comparison of geometrical isomerization of unsaturated fatty acids in selected commercially refined oils. Grasas y Aceites, 62: 284-289. DOI: http: / / dx.doi.org/10.3989 / gya.102310.

United States Food and Drug Administration (USFDA) (2015). Final determination regarding partially hydrogenated oils. Fed. Regist, 80: 116.

Vingering, N; Oseredczuk, M; du Chaffaut, L; Ireland, J and Ledoux, M (2010). Fatty acid composition of commercial vegetable oils from the French market analysed using a long highly polar column. OCL-Ol. Corps. Gras. Li., 17: 185-192. DOI: https: / / doi.org/10.1051/ocl.2010.0309.

Wanders, A; Zock, P and Brouwer, I (2017). Trans fat intake and its dietary sources in general populations worldwide: A systematic review. Nutrients, 9: 840. DOI: https: / / doi.org/10.3390/nu9080840.

Withana-Gamage, T S; Perera, S P and Wanasundara, U N (2005). Coconut Oil. Bailey's Industrial Oil and Fat Products, (Shahidi, F ed.). John Wiley and Sons, Ltd., Hoboken, NJ. DOI: https: / / doi.org/10.1002/047167849X.bio054.pub2.

Wolff, R L (1992). Trans-polyunsaturated fatty acids in French edible rapeseed and soybean oils. J. Amer. Oil Chem. Soc., 69: 106-110. DOI: https: / / doi. org / 10.1007 / BF02540558.

Wolff, R L (1993). Further studies on artificial geometrical isomers of $\alpha$-linolenic acid in edible linolenic acid-containing oils. J. Amer. Oil Chem. Soc., 70: 219-224. DOI: https://doi.org/10.1007/ BF02545298.

World Health Organization and Brouwer, Ingeborg A (2016). Effect of trans-fatty acid intake on blood lipids and lipoproteins: a systematic review and meta-regression analysis. World Health Organization. https://apps.who.int/iris / handle/10665/246109, accessed on 14 May 2020.

World Health Organization (2019). Countdown to 2023: WHO report on global trans fat elimination 2019. World Health Organization, 1-40. https: / / www. who.int/ docs / default-source / documents / replace-transfats / report-on-tfaelimination-2019.pdf?sfvrsn =c9378613_4, accessed on 14 May 2020.

Zady, M F (2000). Correlation and simple least squares regression. http://www.westgard.com/ lesson44.htm, accessed on 14 May 2020.

Zuchowska-Grzywacz, M and Kowalska, M (2019). Trans fatty acids in food-current legal regulations as protections for consumers and food manufacturers. Acta Aliment., 48: 105-114. DOI: https://doi. org/10.1556/066.2019.48.1.12. 